\title{
Adsorptive Separation of Metal Ions with Surface Modified Desmostachya bipinnata
}

\author{
Jagjit Kour, Puspa Lal Homagai, Megh Raj Pokhrel and Kedar Nath Ghimire \\ Central Department of Chemistry \\ Tribhuvan University, \\ Kirtipur, Kathmandu \\ e-mail:jagjit_kour@hotmail.com
}

\begin{abstract}
The biomass of Desmostachy bipannata (Kush, a religious plant of Hindus) was modified for the better adsorption of metal ions from aqueous solution. The FTIR and SEM images were used for the characterization of biomass. The adsorptive separation of metal ions from aqueous solution was studied with equilibrium isotherm and kinetic model. Langmuir adsorption isotherm and pseudo second order kinetic model showed better explanation for the adsorption process. The experimental results suggest that biomass from Kush can be used as an effective biosorbent for the removal of metal ions from aqueous solution.
\end{abstract}

Key words: biomass, biosorbent, Desmostachy bipinnata, langmuir adsorption isotherm, metal ions

\section{Introduction}

Water and soil pollutions are of great concern since they directly affect human health, aquatic

lives and finally the environment (Ali et al. 1997). One of the major causes of pollution is due to liquid wastes discharged from different industries, mining and agricultural activities. The most common toxic metals found in industrial waste water are $\mathrm{Pb}, \mathrm{Cd}, \mathrm{Hg}, \mathrm{Ni}, \mathrm{Cr}$, Cu and Zn (Joshi et al. 1987, Ayyappan et al. 2005)

One of the problems caused by zinc is due to the liquid waste discharged from metal plating, brass manufacturing, refineries and plumbing into water bodies. Zinc is an essential element for human being since it is a cofactor of many enzymes. Its maximum permissible limit is $15 \mathrm{mg}$ but its extensive intake can cause damage to nervous membranes and also corrosive effect on skin (Alluri et al. 2007). It can cause urinary complication as well as cholesterol. U.S. (FDA) has stated that zinc damages nerve receptors in the nose, which can cause anosmia. Hence effective removal of heavy metal ions is important in the protection of environmental quality and public health (Jin et al. 2002). The use of natural materials of biological origin for the removal of heavy metals is becoming popular since they are environmental friendly, economical and can be reused (Alluri et al. 2007). Being bio-waste, they are available in large quantities from agricultural operations, Fruit processing ( Homagai et al.2011, Thirumavalavan et al. 2010), forestry, poultry, fishery, which may have potential to remove heavy metals effectively (Yun et al. 2001, Ahmed et al. 2011).

These materials are recognized as potential alternative to conventional technologies such as precipitation, ion exchange and solvent extraction for the removal of heavy metals since these processes have technical as well as economical constraints (Deng et al. 2005). In the present study a religious plant called Kush (Desmostachya bipinnata) in Nepali was used as biosorbent. It is a holy plant used in all religious activities in Hindu religion. The surface of biosorbent is modified with hydrazine monohydrate to introduce amine functional group for the better adsorption of heavy metals from waste water (Osvaldo et al. 2007, Deng et al. 2003).

\section{Methodology}

A standard stock solution (1000 mg/l) of zinc was prepared in deionised water from its nitrate salt. All 
the working solutions of different concentrations from 25-800 mg/l were prepared by diluting standard stock solution with $0.1 \mathrm{M}$. nitric acid. In all working solutions 0.1 M HEPES (2-[4-(2- Hydroxy methyl)-1-piperazinyl] ethane sulphonic acid) was used as buffering agent (Ghimire et al. 2007). The $\mathrm{pH}$ of the working solutions was adjusted by adding dilute nitric acid and sodium hydroxide solutions. All the reagents and chemicals used in this study were of analytical grade. Dried powder of Kush plant was charred with sulphuric acid. Then it was washed with distilled water till neutrality to remove excess of acid and any other soluble substances, followed by drying in sun and finally in an air oven at $70^{\circ} \mathrm{C}$ for $24 \mathrm{~h}$. Amine functional groups were introduced on the surface of Kush powder by treating with hydrazine monohydrate, which is regarded as surface modified Kush (SMK) and ready for adsorption experiments.

\section{pHstudy}

$\mathrm{pH}$ is one of the important parameters for the sorption of metal ions onto biosorbent. It affects the surface charge and degree of ionization of adsorbent. Batch adsorption tests for $\mathrm{Zn}$ (II) ions removal were performed by keeping the concentration of $\mathrm{Zn}$ (II) metal ions constant $(50 \mathrm{mg} / \mathrm{l})$ as the function of $\mathrm{pH}$ from 1-7. All batch experiments were performed in 50 $\mathrm{ml}$ Erlenmeyer flasks taking $25 \mathrm{mg}$ of dried bioadsorbent (SMK) with $20 \mathrm{ml}$ of metal ions solution. The flasks were agitated in a shaker at lab temperature at $150 \mathrm{rpm}$ for $24 \mathrm{~h}$ to attain equilibrium. After attaining equilibrium, solutions were filtered through cellulose free filter paper and their concentrations were measured using (ICP-AES) inductively coupled plasma atomic emission spectrophotometer (SPECTRO, Analytical Instrument, Kleve, German). The adsorbed amount of metal ions were calculated from the decrease in the metal ions concentration from which percentage adsorption were calculated as follows,

$$
A \%=\frac{C_{1}-C_{e}}{C_{1}} \times 100
$$

\section{Study of adsorption isotherms}

The metal uptake capacity of surface modified Kush (SMK) for Zn (II) was measured using batch experiment by taking $25 \mathrm{mg}$ of biosorbent (SMK) together with 20 $\mathrm{ml}$ of metal ions solution of different concentrations ranging from $25,50,100,200,400,600$ and $800 \mathrm{mg} / \mathrm{l}$ at optimum pH- 6 in $50 \mathrm{ml}$ Erlenmeyer flask. The flasks were shaken in a shaker at lab temperature at $150 \mathrm{rpm}$ for $24 \mathrm{~h}$ to attain the equilibrium. After $24 \mathrm{~h}$, the solutions were filtered then initial and equilibrium concentrations of the respective metal ions were measured using ICP-AES. The sorption capacity of metal ions is the concentration of the metal ions onto the adsorbent, which can be calculated from the mass balance principle,

$$
q=\frac{\mathrm{C}_{i}-\mathrm{C}_{\mathrm{e}}}{\mathrm{W}} \times \frac{\mathrm{L}}{1000}
$$

In the above equation (1) and (2), q represents the amount of metal up taken per unit mass of the adsorbent (mg/g), $\mathrm{l}$ is the volume of the test solution $(\mathrm{ml}), \mathrm{W}$ is the dry mass of the adsorbent $(\mathrm{g})$ and $\mathrm{C}_{\mathrm{i}}$ and $\mathrm{C}_{\mathrm{e}}$ are the initial and final concentrations (mg/l), respectively.

\section{Kinetic studies}

Kinetic studies of adsorption are helpful to find the rate at which the metals are removed from aqueous solution. For the kinetic study $25 \mathrm{mg}$ of biosorbent (SMK) was taken into a $50 \mathrm{ml}$ Erlenmeyer flask together with $20 \mathrm{ml}$ of working solutions of respective metal ions of $50 \mathrm{mg} / \mathrm{l}$.

The $\mathrm{pH}$ of the metal ion solutions was maintained at their optimum $\mathrm{pH}$. The flasks were shaken in a shaker at lab temperature at $150 \mathrm{rpm}$. The metal ions concentrations were measured at 14 different contact time ranging from 5-360 min. At the end of each contact time, the metal ions solution was filtered and the filtrate was analyzed using ICP-AES. The amount of metal ions adsorbed at certain time (t) was calculated from the mass adsorption rates of metal ions onto the biosorbent.

\section{Results and Discussion}

\section{Instrumental analysis}

The surface morphology of unmodified Kush (UMK) and surface modified Kush (SMK) were analyzed with the help of scanning electron microscope (SEM). The SEM microphotographs of unmodified Kush showed smooth and even surface as shown in Fig.1. (a) whereas the surface modified Kush showed the porous and rough surface morphology as shown in Fig.1 (b) . This result suggests the chemical modification on the surface of biosorbent. 


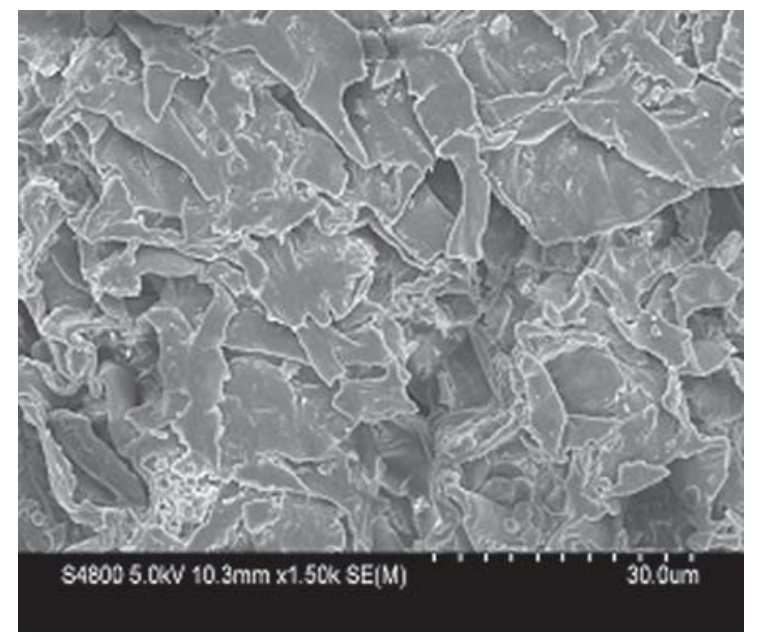

Fig. 1(a)

Fig.1. (a) Scanning electron microscope (SEM) photographs of unmodified Kush (UMK)

The type of functional groups present on the unmodified Kush (UMK)) were analyzed using diffuse refrectance infrared spectroscopy (DFTIR) (Harrick scientific corporation). The intense sharp adsorption peak at $3411 \mathrm{~cm}^{-1}$ in Fig. 2. can be assigned to the (O$\mathrm{H})$ stretching vibration due to inter and intra molecular

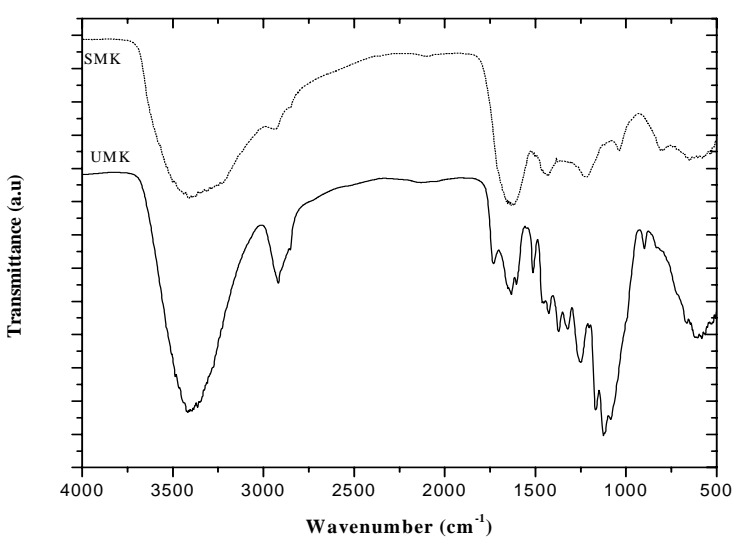

Fig 2. Diffuse refrectance infrared spectroscopy (DFTIR) of unmodified Kush( UMK) And surface modified Kush (SMK)

hydrogen bonding of polymeric compounds like alcohols, phenols and carboxylic acids as in cellulose, hemicelluloses and lignin, indicating the presence of free hydroxyl groups on the biosorbent surface. The peak around $2926 \mathrm{~cm}^{-1}$ corresponds to $(\mathrm{C}-\mathrm{H})$ stretching in $\mathrm{CH}_{2}$ and $\mathrm{CH}_{3}$ groups. Similarly, the peak around 1736 $\mathrm{cm}^{-1}$ corresponds to carbonyl $(\mathrm{C}=\mathrm{O})$ stretching

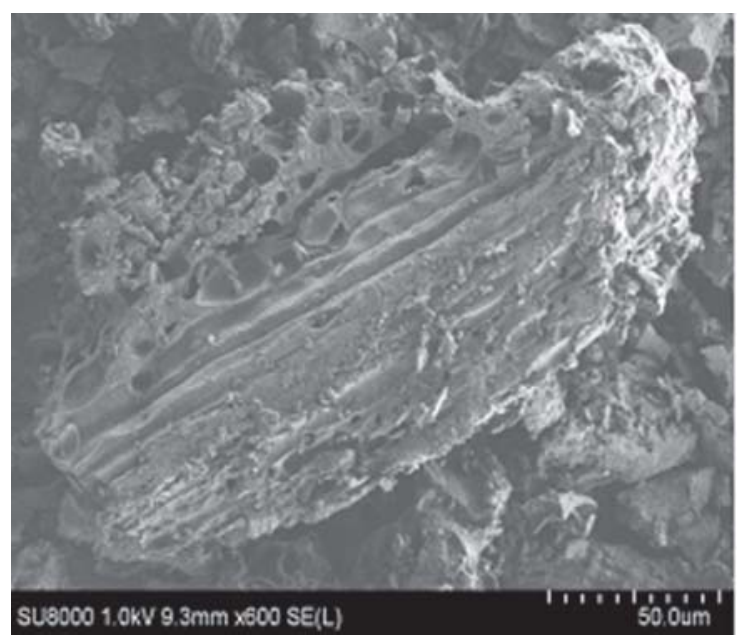

Fig. 1(b)

Fig.1. (b) Scanning electron microscope (SEM) photographs of surface modified Kush (SMK)

vibration. Peak around 1426-1377 $\mathrm{cm}^{-1}$ was due to (O$\mathrm{H}$ ) bending vibration, $1169-1082 \mathrm{~cm}^{-1}$ was due to (C-O) stretching vibration of alcohol (Silverstein et al. 1981, Shriner et al. 1998).

A sharp difference in IR spectra was noticed in the surface modified Kush (SMK) as shown in Fig. 2. The intense sharp peak at $3411 \mathrm{~cm}^{-1}$ in UMK has been shifted to $3392 \mathrm{~cm}^{-1}$ as a broad peak in SMK (Deng et al. 2003) which is due to the overlapping of the hydroxyl group with amine group. This also suggests the introduction of amine group onto the surface of biosorbent.

The elemental analysis of unmodified Kush showed presence of $1.13 \%$ nitrogen. After surface modification, nitrogen was increased up to $7.56 \%$, which further supported the fact that there was introduction of amine functional group onto the biosorbent.

\section{Effect of pH on adsorption of Zn (II) metal ions}

The $\mathrm{pH}$ of aqueous solution is one of the important factors for adsorption. At low solution $\mathrm{pH}$, large quantity of hydronium ions $\left(\mathrm{H}_{3} \mathrm{O}^{+}\right)$in solution will compete with the metal ions for binding on the functional groups onto the adsorbent surface. Hence, there would be decrease in adsorption of metal ions. But the adsorption of metal ions increases with the increase in $\mathrm{pH}$, due to the decrease in competition between hydronium ions $\left(\mathrm{H}_{3} \mathrm{O}^{+}\right)$and metal ions for the active sites on the sorbent surface, however, decrease 
in adsorption will be observed after certain $\mathrm{pH}$ owing to the hydrolysis of metal ions as well as the increased concentration of hydroxyl ions or anionic species in the medium. The maximum adsorption of Zn (II) metal ions were found at their optimum $\mathrm{pH}-6$, as shown in Fig.3. The small decrease in the removal of metal ions at higher $\mathrm{pH}$ values were due to the formation of hydroxides of the $\mathrm{Zn}$ (II) metal ions.

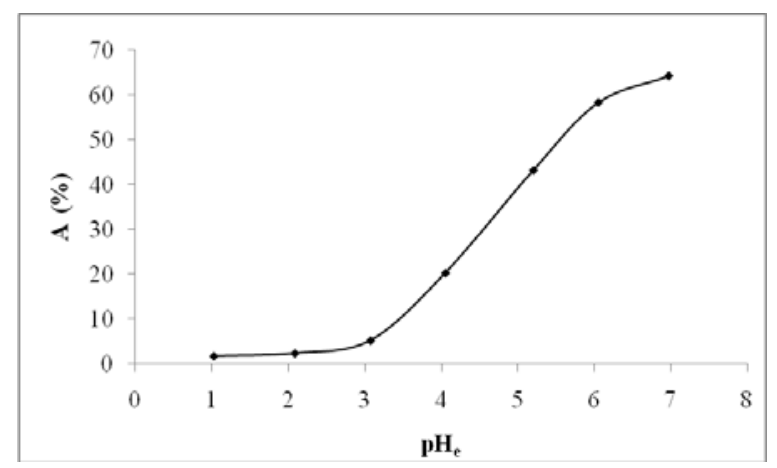

Fig.3 . Effect of pH in the adsorption of Zn (II) onto surface modified Kush (SMK)

\section{Adsorption isotherms}

Adsorption isotherm helps to determine the maximum adsorption capacity of biosorbent for adsorbing different metal ions as well as useful for designing an optimized adsorption process. The maximum adsorption capacity of the surface modified Kush for $\mathrm{Zn}$ (II) metal ions were investigated at different metal ions concentrations from $25-800 \mathrm{mg} / \mathrm{l}$ as shown in Fig. 4. Batch adsorption experiments were carried out by taking $25 \mathrm{mg}$ adsorbent in $20 \mathrm{ml}$ of $\mathrm{Zn}$ (II) solution at their equilibrium $\mathrm{pH}-6$ in Erlenmeyer flask. The solutions were equilibrated for $24 \mathrm{~h}$ to attain equilibrium and the sorption isotherms were evaluated using the linearized Langmuir model represented by

equation (3).

$$
\frac{C_{e}}{q_{e}}=\frac{1}{q_{m} b}+\frac{C_{e}}{q_{m}}
$$

Where $\mathrm{q}_{\mathrm{e}}(\mathrm{mg} / \mathrm{g})$ is the amount of adsorbed metal ions per gram of adsorbent, $\mathrm{C}_{\mathrm{e}}(\mathrm{mg} / \mathrm{l})$ is the residual concentration of metal ions after adsorption, $\mathrm{q}_{\mathrm{m}}(\mathrm{mg} / \mathrm{g}$ ) is the maximum adsorption capacity and $b(\mathrm{l} / \mathrm{mg})$ is the binding constant.

The Langmuir constant and its correlation coefficients evaluated from the isotherms for $\mathrm{Zn}$ (II) is 0.99 . The correlation coefficient $\left(\mathrm{R}^{2}\right)$ of the Langmuir plot is high,

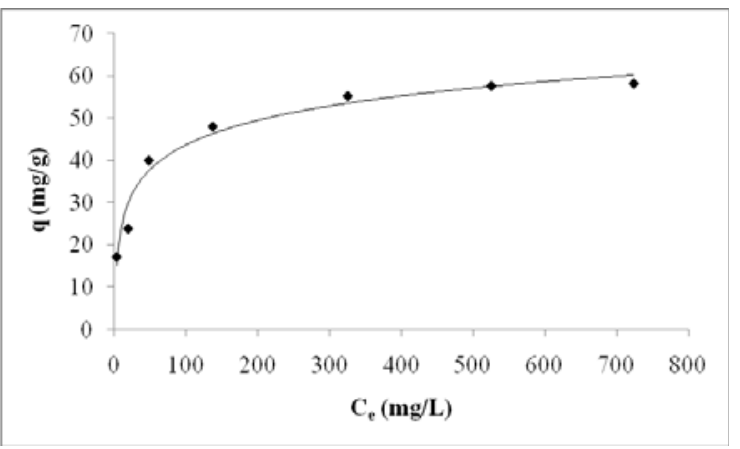

Fig.4 . Adsorption isotherm for the Zn (II) onto surface modified Kush (SMK)

which suggested that the equilibrium adsorption of $\mathrm{Zn}$ (II) metal ions onto the biosorbent could be best described with the Langmuir isotherm. The maximum amount of metal ions adsorbed $\left(\mathrm{q}_{\mathrm{m}}\right)$ based on experimental data is $58.16 \mathrm{mg} / \mathrm{g}$. On the other hand, the theoretical monolayer capacity $\left(\mathrm{q}_{\max }\right)$ of the respective metal ions based on the Langmuir adsorption equation is found to be $62.50 \mathrm{mg} / \mathrm{g}$, (Table.1.) which reveals that the active sites of biosorbent are constant and independent of the metal solutions used. The above results are in close agreement with each other suggesting that heavy metals can be quantatively sequester onto the surface modified Kush (SMK). The adsorption capacity of biosorbent was found to be increased with an increase in the initial concentration of metal ions from 25- 200 $\mathrm{mg} / \mathrm{l}$ in solution and after that it remained almost constant forming platue. This is because during the initial concentration of 25 - $200 \mathrm{mg} / \mathrm{l}$, the active sites of the adsorbents were almost gradually filled by metal ions, and hence the adsorption activity of adsorbent is limited. So, further increase in initial concentration of metal ions result in no more adsorption, due to unavailability of adsorption sites. The correlation coefficient $\left(\mathrm{R}^{2}\right)$ value was found to be 0.99 indicating that the Langmuir isotherm model fitted well as shown in Fig.5. No any information is available in literature on the adsorption of Kush to compare with our findings.

Table 1. Langmuir adsorption isotherm model parameters and experimental $\mathrm{q}_{\max }$

\begin{tabular}{l|c|c|c|c}
\hline Metal ions & $\begin{array}{l}\text { Langmuir } \\
\mathrm{q}_{\max }(\mathrm{mg} / \mathrm{g})\end{array}$ & $\begin{array}{l}\text { Experimental } \\
\mathrm{q}_{\max }(\mathrm{mg} / \mathrm{g})\end{array}$ & $\mathrm{b}(\mathrm{L} / \mathrm{mg})$ & $\mathrm{R}^{2}$ \\
\hline Zn (II) & 62.50 & 58.16 & 0.037 & 0.99 \\
\hline
\end{tabular}




\section{J. Kour et al./Adsorptive Separation........}

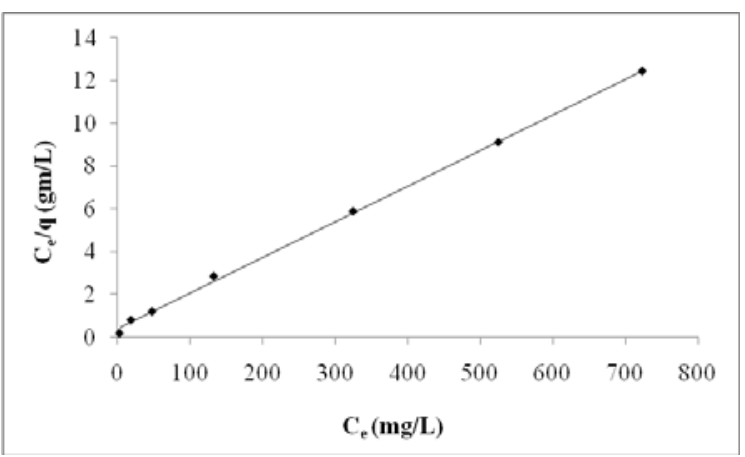

Fig.5 . Langmuir plot for the adsorption of Zn (II) onto surface modified Kush (SMK)

\section{Kinetic study}

Sorption kinetics is an important parameter to predict the rate and time at which the pollutant is removed from aqueous solution. Several kinetic models are described to investigate the reaction order in sorption systems. However, over the past few years, pseudo second order kinetic model has been considered to be among the most appropriate. In the present study, the sorption kinetics onto SMK was analyzed by taking $50 \mathrm{mg} / \mathrm{l}$ initial concentration of Zn (II) metal ions at its optimum $\mathrm{pH}$. The sorption kinetics were studied at different time intervals ranging from 5-360 min. The final concentrations of $\mathrm{Zn}$ (II) metal ions were measured using ICP-AES after shaking for required interval of time for each sample solution. The experimental data showed the increase in adsorption percentage with the increase in time from $5-120 \mathrm{~min}$ and then it became almost constant as shown in Fig.6. All the kinetic data of the respective metal ions were tested using the pseudo first order and pseudo second

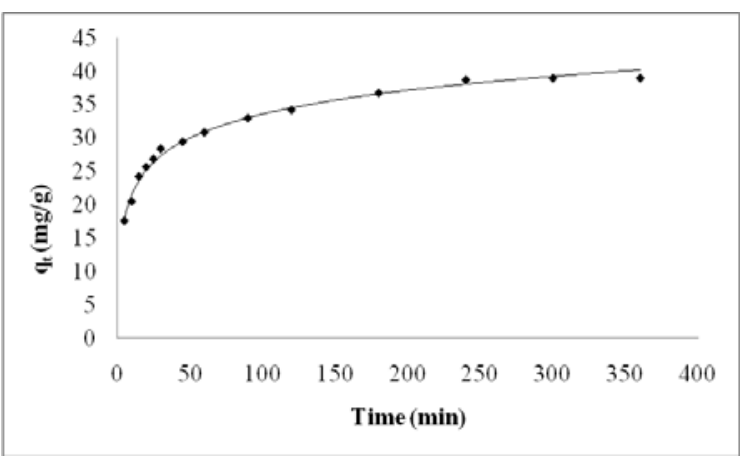

Fig.6 . Adsorption kinetics of Zn (II) onto surface modified Kush (SMK) order rate equation. In case of first order rate equation, data were poorly fitted (data and figure not given) and the Lagergren correlation coefficient $\left(\mathrm{R}^{2}\right)$ value were very low. Therefore pseudo- second order kinetic model has been used to evaluate the experimental kinetics adsorption data given by Ho and McKay (Ho et al. 1999).

$$
\frac{t}{\mathrm{q}_{\mathrm{t}}}=\frac{1}{K_{2} q_{e}^{2}}+\frac{\mathrm{t}}{q_{e}}
$$

Where $\mathrm{q}_{\mathrm{t}}(\mathrm{mg} / \mathrm{g})$ is the amount of the adsorption at time $\mathrm{t}(\mathrm{min}), \mathrm{K}_{2}(\mathrm{~g} / \mathrm{mg} / \mathrm{min})$ is the rate constant of the pseudo- second order kinetic adsorption. The straight line plot of $t / q_{t}$ versus $t$, as shown in Fig.7. has been used to obtain the rate parameters.

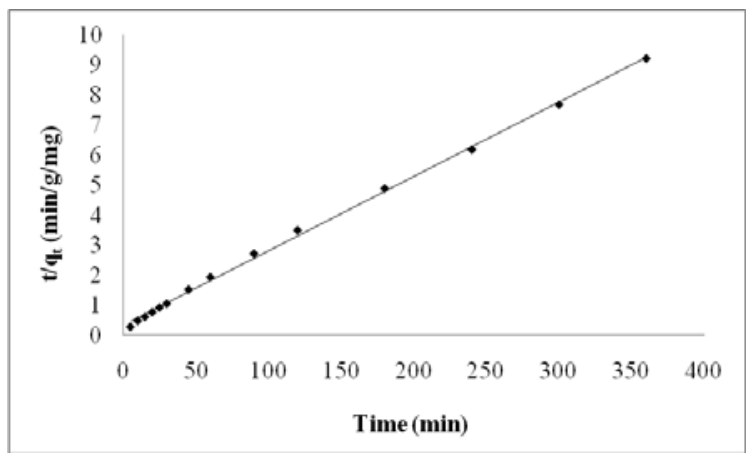

Fig.7 . Pseudo second- order kinetic model in the adsorption of Zn (II) onto surface modified Kush (SMK)

The calculated $q_{e}$ value is in agreement with those of experimentally obtained $q_{e}$ for the pseudo- second order model. The $\mathrm{R}^{2}$ value for $\mathrm{Zn}$ metal ions concentration obtained by fitting the experimental data to equation (4) was higher than 0.99 , which indicates the applicability of the model for the entire adsorption process and also confirmed the chemisorptions of the respective metal ions onto the SMK.

Surface of Kush were chemically modified with hydrazine monohydrate to introduce amine functional groups onto the polymeric surface of the biosorbent. A new biosorbent is explored, which is eco-friendly and easily available. Instrumental analysis suggested that the amine groups were introduced onto the surface of biosorbent, which were responsible for the quantitative adsorption. Batch adsorption experiments performed for adsorption isotherm and kinetic studies at their optimum $\mathrm{pH}$ revealed that SMK has appreciable capacity to adsorb Zn (II) metal ions from waste water. 
However, further studies concerning the recovery and recycling of biosorbent should be carried out to investigate the cost effectiveness and potential application in the waste water treatment.

\section{Acknowledgements}

J. Kour one of the authors would like to thank the cultural and scientific agreement programme between Padua University and Tribhuvan University (Prof. Caravello and Prof. Promod. K. Jha) for financing this research and University Grant Commission, Bhaktapur, Nepal for the Ph. D. fellowship.

\section{References}

Ahmed, S.A. 2011. Batch and fixed-bed column techniques for removal of $\mathrm{Cu}$ (II) and $\mathrm{Fe}$ (III) using carbohydrate natural polymer modified complexing agents. Carboh. Polym. 83: 1470-1478.

Ali. M and P.A N. Mohammed. 1997. Treatment methods for the removal of heavy metal pollutants from water and wastewater. J. Ind .Pollut. Control 13: 85-106.

Alluri, H.K., S.R. Ronda, V.S. Settalluri, J.S. Bondili, V. Suryanarayana and P. Venkateshwar. 2007. Biosorption: An eco-friendly alternative for heavy metal removal: Review. African. J. Bio. Technol 6 (25): 2924-2931.

Ayyappan R., A. Carmalin Sophia, K. Swaminathan and S. Sandhya. 2005. Removal of $\mathrm{Pb}$ (II) from aqueous solution using carbon derived from agricultural wastes. Process Biochemistry 40: 1293-1299.

Deng, S. and Y.P. Ting. 2005. Fungal biomass with grafted polyacrylic acid for enhancement of $\mathrm{Cu}$ (II) and $\mathrm{Cd}$ (II) biosorption. Langmuir. 21: 5940-5948.

Deng, S.R., R.B. Bai and J.P. Chen. 2003. Aminated polyacrylontrile fibers for lead and copper removal. Langmuir 19: 5058- 5064.

Ghimire, K. N., K. Inoue, K. Ohto and T. Hayashida. 2007. Adsorptive separation of metallic pollutants onto waste seaweeds, Porphyra yezoensis and Ulva japonica. Separation Science and Technology 42(9): 2003-2018.
Ho, Y.S. and G. McKay. 1999. Pseudo-second order model for sorption process. Process. Biochem 34: 451-465.

Homagai, P.L., K.N. Ghimire and K. Inoue. 2011. Preparation and characterization of charred xanthated sugarcane bagasse for the separation of heavy metals from aqueous solutions. Sep. Sci. Technol 46: 330339.

Jin, L. and R.B. Bai. 2002. Mechanisms of lead adsorption on chitosan /PVA hydrogel beads Langmuir 18: 97659770.

Joshi, S. 1987. Study of toxicity of Pb (II) on fresh water pond snail Lymnea luteola. Graduate degree thesis, University of Poona, India, $51 \mathrm{p}$.

Ngah, W.S.W. and M.A.K.M. Hanafiah. 2008. Removal of heavy metal ions from wastewater by chemically modified plant wastes as adsorbents: A review. Bioresource 99: 3935- 3948.

Osvaldo Karnitz Jr., Leandro Vinicius Alves Gurgel, Julio Cesar Perin de Melo, Vagner Roberto Botaro, Tania Marcia Sacramento Melo, Rossimiriam Pereira de Freitas Gil and Laurent Frederic Gil. 2007. Adsorption of heavy metal ion from aqueous single metal solution by chemically modified sugarcane bagasse. Bioresour.Technol 98: 1291-1297.

Shriner, R.L., C.K.F. Hermann, T.C. Morrill, D.Y. Curtin and R.C. Fuson. 1998. The systematic identification of organic compounds, $7^{\text {th }}$ ed. Wiley, New York. 324 pp. Silverstein R.M., G.C. Bassler and T.C. Morril. 1981. Spectrometric identification of organic compounds. John Willey and Sons: New York, 95 p.

Thirumavalavan, M., Y.L. Lai, L.C. Lin and J.F. Lee. 2010. Cellulose- Based Native and Modified Fruit Peels for the Adsorption of Heavy Metal Ions from aqueous Solution: Langmuir Adsorption Isotherms. J. Chem. Eng. Data 55: 1186.

Volesky, B. 1990. Removal and recovery of heavy metals by biosorption. In Biosorption of heavy metals (Ed. B. Volesky). Boca Raton: CRC Press. Pp. 12-31.

Yun, Y.S., J.M. Park and B. Volesky. 2001. Biosorption of trivalent chromium on the brown seaweed biomass. Environ. Sci. Technol 35: 4353-4358. 